\title{
Evaluation of an enzyme immunoassay kit for detecting cryptosporidium in faeces and environmental samples
}

\author{
C A Siddons, P A Chapman, B A Rush
}

\begin{abstract}
Aims: To evaluate a commercially available enzyme immunoassay based on a monoclonal antibody to a genus specific Cryptosporidium (IDEIA Cryptosporidium; Dako) antigen for detecting Cryptosporidium oocysts in faecal and environmental samples.

Methods: 435 human faecal samples and post-filtration deposits from 10 reservoir samples, and from six tap water samples seeded with Cryptosporidium oocysts, were examined by EIA according to the manufacturer's instructions, and by microscopic examination of phenolauramine stained smears. Samples giving discrepant results were examined by specific immunofluorescence, before and after concentration of oocysts.
\end{abstract}

Results: Sixteen (3.6\%) faecal samples were positive by both microscopy and EIA; five $(1 \cdot 1 \%)$ were positive by microscopy of auramine-phenol stained smears (but were not confirmed by specific immunofluorescence) and negative by EIA; one ( $0.2 \%)$ was positive by EIA alone, but confirmed by specific immunofluorescence; and 362 (83.2\%) were negative by both microscopy and EIA. Compared with immunofluorescence positive faecal samples, the sensitivity of conventional microscopy and EIA were $94 \%$ and $100 \%$, and specificity $76.4 \%$ and $100 \%$, respectively. Fifty one $(11.7 \%)$ were not examined by microscopy due to detection of other pathogens in a previous sample from that patient, but were found to be negative by EIA. Ten reservoir water samples (not suspected of being linked to cases of cryptosporidiosis) were negative by both microscopy and EIA. Of six samples of tap water seeded with varying concentrations of Cryptosporidium oocysts, two $\left(10^{2}\right.$ and $10^{3}$ oocysts/1) were positive by both microscopy and EIA, two (10 and 1/1) by EIA alone, and two (0.1/1 and unseeded water) were negative by both microscopy and EIA.

Conclusions: The kit is simple and rapid to use and offers a less subjective method than microscopy for detecting Cryptosporidium in faecal samples submitted to a busy diagnostic laboratory.

Cryptosporidium, a coccidian parasite, is now recognised worldwide as an important intestinal pathogen that causes diarrhoeal disease in man and animals. ${ }^{1}$ The source of infection for man is diverse and may include close contact with animals, infection in domestic and farm animals being common. ${ }^{2-4}$ Transmission of Cryptosporidium from animals via food and milk has been documented, ${ }^{56}$ as has personto-person transmission in hospitals and nurseries. $^{78} \mathrm{~A}$ recent cause for concern to public health authorities has been outbreaks of cryptosporidiosis, possibly associated with contaminated drinking water supplies that had been treated by conventional means to remove bacterial and viral pathogens. ${ }^{-11}$ Two outbreaks associated with swimming pools have also been reported. ${ }^{12} 13$

Microscopic detection of Cryptosporidium in water samples is both laborious and costly. Enzyme immunoassays (EIAs) have been developed by two groups ${ }^{14}$ as alternatives to microscopy for detecting Cryptosporidium in faeces and environmental samples.

\section{Methods}

Four hundred and thirty five faecal samples were taken from those submitted to Sheffield Public Health Laboratory over a two month period. Each specimen was examined by standard methods (on a selective basis using information supplied on the request form) for salmonellae, campylobacters, shigellae, ova, cysts and mature parasites, vibrios and enteropathogenic Escherichia coli. A $10 \%$ suspension of faeces was made in diluent provided in the EIA kit and allowed to settle for 10 minutes before use in the EIA. Known positive samples were titrated over a range of dilutions from 1 in 10 to 1 in 160 and tested using the EIA. Samples known to contain various other pathogens, or their toxins, either naturally or added in the laboratory, were examined by EIA to check for cross-reactivity. Naturally occurring pathogens in the faecal samples examined were salmonellae ( $n=13)$, campylobacters ( $n$ $=3$ ), adenovirus $(n=7)$, astrovirus $(n=1)$, coronavirus $(n=1)$, small round virus $(n=8)$, rotavirus ( $n=7)$, ova, cysts and mature parasites $(\mathrm{n}=9)$ and those where Clostridium difficile cytotoxin was detected $(n=6)$. Pathogens or their toxins(s) added to a negative faecal sample were Aeromonas hydrophila $(\mathbf{n}=1)$, Clostridium perfringens enterotoxin $\mathrm{A}(\mathrm{n}=1)$, enteropathogenic $E$ coli $(\mathbf{n}=3)$, enterotoxigenic $E$ coli $(\mathrm{n}=2)$, Plesiomonas shigelloides ( $\mathrm{n}$ $=2)$, Shigella flexneri $2 \mathrm{a}(\mathrm{n}=1)$, Shigella sonnei $(\mathrm{n}=1)$, Verotoxin producing $E \operatorname{coli}(\mathrm{n}=$ 2), Vibrio alginolyticus $(\mathrm{n}=1)$ and Vibrio parahaemolyticus $(n=1)$. For each pathogen $100 \mu \mathrm{l}$ of overnight broth culture was added to $900 \mu \mathrm{l}$ of faecal sample; about $100 \mu \mathrm{g}$ of 
Clostridium perfringens enterotoxin was added to $1 \mathrm{ml}$ of faecal sample.

Ten 201 reservoir water samples, not suspected of being linked to cases of cryptosporidiosis, were collected by Sheffield Environmental Health Department. They were filtered through a $0.45 \mu \mathrm{m}$ membrane filter (Pall Process Filtration Ltd) and the membranes were cut into small pieces and agitated in 100 $\mathrm{ml}$ phosphate buffered saline (PBS) with Tween-20 $0 \cdot 1 \% \mathrm{v} / \mathrm{v}$, to release any deposit. The resulting suspension was centrifuged at $3000 \times g$ at $4^{\circ} \mathrm{C}$ for 20 minutes. The supernate was discarded and the deposit was resuspended in $200 \mu$ of PBS.

Cryptosporidium oocysts semi-purified from human faecal samples by previously described methods, ${ }^{16}$ were used to seed 501 volumes of tap water with either $10^{3}, 10^{2}, 10,1$ or $0 \cdot 1$ oocysts/1; unseeded tap water was used as a negative control. Water samples were filtered and processed as above, but the deposit was suspended in $5 \mathrm{ml}$ of PBS.

\section{MICROSCOPY}

Air dried smears of faeces were stained by an auramine-phenol method ${ }^{17}$ and examined by ultraviolet light microscopy. Smears of water deposits were examined as described previously. ${ }^{11}$

\section{ENZYME IMMUNOASSAY (EIA)}

Microwells coated with a monoclonal antibody specific for $C$ parvum, $C$ muris, and $C$ baileyi are used to capture Cryptosporidium oocysts from faecal suspensions or environmental samples, which are then detected by horseradish peroxidase-labelled monoclonal antibody and substrate.

Each assay run included a positive and a negative control, and for the purposes of the trial three quality assessment controls (nonreactive, strongly reactive, and weakly reactive) provided by the suppliers. For the test two drops (using droppers provided with the kit, about $100 \mu \mathrm{l}$ ) of each sample was added to one microwell, mixed, covered, and incubated at ambient temperature $\left(18-28^{\circ} \mathrm{C}\right)$ for 30 minutes. The microwells were washed five times with the wash solution provided, by filling wells to overflowing, emptying, and tapping dry on absorbent paper for each wash. Two drops (100 $\mu 1)$ of Cryptosporidium conjugate were added to each microwell mixed, covered, incubated at ambient temperature for a further 30 minutes, and washed as above. Two drops $(100 \mu \mathrm{l})$ of substrate part $\mathbf{A}$ (hydrogen peroxide) followed by two drops $(100 \mu \mathrm{l})$ of substrate part B (tetramethylbenzidine) were added to each

Table 1 Detection of Cryptosporidium by microscopy and EIA

\begin{tabular}{llllll}
\hline & \multicolumn{2}{l}{ Number of specimens positive by: } & & Number negative by: \\
\cline { 2 - 5 } \cline { 3 - 5 } Type of specimen & $: \begin{array}{l}\text { Microscopy } \\
\text { and EIA }\end{array}$ & $\begin{array}{l}\text { Microscopy } \\
\text { alone }\end{array}$ & $\begin{array}{l}\text { EIA } \\
\text { alone }\end{array}$ & & Microscopy and EIA \\
\hline Human faeces $(\mathrm{n}=435)^{\star}$ & 16 & 5 & 1 & 362 \\
Reservoir waters $(\mathrm{n}=10)$ & 0 & 0 & 0 & 10 \\
\hline
\end{tabular}

* 51 of 435 were not examined by routine microscopy due to prior detection of other pathogens microwell. The contents were carefully mixed by gently agitating the whole plate in a swirling motion. The microwells were covered and left at ambient temperature for 15 minutes, avoiding direct sunlight. At this stage the plates were read visually and positive reactions (a definite blue colour) were recorded before adding two drops $(100 \mu \mathrm{l})$ of $1 \mathrm{~N}$ sulphuric acid to each microwell to stop the enzyme action. The contents of the microwells were mixed briefly and the $\mathrm{OD}_{450}$ read on a Dynatech MR 500 plate reader within 15 minutes.

Results were calculated in concurrence with kit instructions. Specimens which produced no visible colour, and after addition of acid an $\mathrm{OD}_{450}$ of less than $0 \cdot 15$, were considered negative, and those which produced a distinct blue colour, and after addition of acid an $\mathrm{OD}_{450}$ more than 0.3 , were considered positive. The test run was accepted as valid if the control samples supplied with the kit met these criteria.

\section{IMMUNOFLUORESCENCE}

This was used when results of EIA and microscopy did not agree. A commercial kit utilising a direct immunofluorescence method based on a mouse monoclonal antibody conjugated to fluorescein isothiocyanate was used according to instructions supplied by the manufacturer (DetectIF Cryptosporidium, Northumbria Biologicals Ltd). If immunofluorescence results were negative the specimen was concentrated using a modified formol-ether method $^{18}$ and retested by immunofluorescence as above.

\section{Results}

A summary of the microscopy and EIA results is shown in table 1. Of 435 human faecal specimens investigated, $16(3.6 \%)$ were positive by both microscopy and EIA, five $(1 \cdot 1 \%)$ were positive by microscopy alone, one $(0.2 \%)$ by EIA alone and $362(83.2 \%)$ were negative by both microscopy and EIA. Fifty one $(11.7 \%)$ were not examined by microscopy due to prior detection of other pathogens but were found to be negative by EIA. Six samples gave discrepant results. Five of these samples were positive by microscopy but negative by EIA, and on further examination of four of them by immunofluorescence, including sample concentration by the designated formol-ether method, all four were negative; there was insufficient of the remaining one sample for examination by immunofluorescence. One specimen which was negative by microscopy but positive by EIA was positive by immunofluorescence (table 2). Compared with faecal samples positive by immunofluorescence, the sensitivity of conventional microscopy and EIA were $94 \%$ and $100 \%$, and specificity $76.4 \%$ and $100 \%$, respectively. All of the samples containing other naturally occurring pathogens and those added in the laboratory gave negative results by EIA. Table 3 shows the microscopy and EIA results of the titration of eight positive faecal samples.

All 10 reservoir samples were negative by both microscopy and EIA. Of the seeded tap water samples, two were found to be positive by 
Table 2 Discrepant results

\begin{tabular}{lllll}
\hline & \multicolumn{4}{l}{ Number of specimens that were positive by: } \\
\cline { 2 - 5 } $\begin{array}{l}\text { Number of } \\
\text { specimens }\end{array}$ & Microscopy & EIA & Immunoflourescence & $\begin{array}{l}\text { Immunofluorescence } \\
\text { after concentration }\end{array}$ \\
\hline 4 & 4 & 0 & 0 & 0 \\
1 & 0 & 1 & 1 & Not examined \\
1 & 1 & 0 & Not examined & Not examined \\
\hline
\end{tabular}

microscopy and EIA; the sample seeded with 100 oocysts $/ 1$ contained 200 oocysts $/ \mathrm{ml}$ of deposit and the sample seeded with 1000 oocysts/1 contained 850 oocysts/ml of deposit. Two further samples were positive by EIA but negative by microscopy-those seeded with 1 and 10 oocysts/1 (table 4). Two samples, one seeded with $0 \cdot 1$ oocysts/1 and one unseeded sample, were negative by both microscopy and EIA.

\section{Discussion}

Diagnosis of cryptosporidiosis presently relies on recognition of the parasite by conventional light microscopy. This is laborious and insensitive, ${ }^{19} 20$ and may be prone to error if staff are inexperienced; difficulties in distinguishing Cryptosporidium oocysts from non-cryptosporidial bodies have been reported. ${ }^{21} 22$

Confirmation of the presence of Cryptosporidium in environmental samples is often difficult, time consuming, and costly. ${ }^{23}$ Oocysts from such samples may stain atypically in conventional and immunofluorescence techniques, ${ }^{24} 25$ and preparing water samples for microscopy may involve sequences of filtration, chemical treatment, flotation and density gradient centrifugation to remove debris and render oocysts visible by microscopy. ${ }^{23-27}$

When comparing microscopy and EIA results it is extremely difficult to relate the concentration of oocysts recognised visually with optical density readings of EIAs (table 3). This may be due in part to detection of either intact oocysts or free antigen by EIA, but detection of only the former by microscopy. In clinical diagnostic use the EIA seems to be at least as sensitive as, and probably of superior specificity to, routine examination of auramine-phenol stained smears, although the number of positive samples examined was small; it is reassuring, however, that the EIA failed to react with any of 51 samples containing other recognised diarrhoeal pathogens or their toxins. Other EIAs suggested that the

Table 3 Microscopy and EIA of titrations of eight faecal samples containing Cryptosporidium

\begin{tabular}{lll}
\hline Sample number & Microscopy & $\begin{array}{l}\text { Last dilution with } \\
\text { OD }\end{array}$ \\
\hline 1 & ++ & $\geqslant 160$ \\
2 & ++ & 80 \\
3 & ++ & $\geqslant 160$ \\
4 & + & $\geqslant 160$ \\
5 & + & 10 \\
6 & +++ & 40 \\
7 & +++ & 10 \\
8 & +++ & + \\
\hline &
\end{tabular}

Table 4 Detection of Cryptosporidium by microscopy and $E I A$ in seeded tap water

\begin{tabular}{|c|c|c|}
\hline $\begin{array}{l}\text { Sample number } \\
\text { (oocysts/litre) }\end{array}$ & Microscopy & $E I A$ \\
\hline $1(0)$ & - & - \\
\hline $2(0 \cdot 1)$ & - & - \\
\hline $3(1.0)$ & - & + \\
\hline $4(10)$ & - & + \\
\hline $5(100)$ & $\stackrel{+}{(200 \text { oocysts/ml deposit) }}$ & + \\
\hline $6(1000)$ & $\stackrel{+}{(850 \text { oocysts } / \mathrm{ml} \text { deposit })}$ & + \\
\hline
\end{tabular}

antigen detected may be either soluble or particulate when positive results were obtained from both faecal suspensions and faecal supernatants. ${ }^{13}$ The same EIA ${ }^{13}$ gave positive results for samples of swimming pool water where oocysts were not demonstrable by microscopy, possibly due to disintegration as they were filtered through sand. ${ }^{16}$ Detection by the EIA of soluble or particulate antigen, the concentration of which may be influenced by sample processing techniques, could be a confounding variable in this, and future comparisons of EIA and microscopy. However, the ability to detect Cryptosporidium by means other than detecting whole intact oocysts may be advantageous, particularly in environmental samples, providing that the methods used are of high specificity.

One specimen was negative by microscopy but positive by EIA and immunofluorescence. An EIA would probably be more sensitive than microscopy of stained smears. Stibbs and Ongerth $^{28}$ used immunofluorescence and auramine-phenol to detect Cryptosporidium oocysts in faecal samples and found that immunofluorescence was significantly more sensitive than auramine-phenol for detection in smears with low oocyst concentrations; our findings would tentatively support this.

The EIA was apparently more sensitive than microscopy in detecting oocysts in seeded tap water samples; this may be due to the inherent sensitivity of EIA relative to microscopy, and to detection by EIAs of disintegrated oocysts. The amount of debris present in deposit from 501 of tap water makes detection of oocysts by microscopy difficult, possibly causing false negative results; such debris does not affect EIA tests.

The kit is simple and rapid to use and offers a less subjective method than microscopy for detecting Cryptosporidium in faecal samples submitted to a busy diagnostic laboratory. The EIA is based on a monoclonal antibody that is genus specific, which is true of other monoclonal antibodies to Cryptosporidium described to date..$^{29}{ }^{30}$ This is unlikely to affect the diagnosis of human infections, which seem to be almost exclusively due to $C$ parvum; specific confirmation of $C$ parvum in faecal or environmental samples awaits development of species specific monoclonal antibodies.

We thank Dako Diagnostics Ltd for providing the kits.

1 Chapman PA. Cryptosporidiosis: recent trends in epidemiology, diagnosis and treatment. Serodiagn Immunother Infect Dis 1988;2:311-7. 
2 Pohlenz J, Moon HW, Cheville NF, Bemrick WJ. Cryptosporidiosis as a probable factor in neonatal diarrhoea of calves. J Am Vet Med Assoc 1978;172:452-7.

3 Tzipori S. Cryptosporidiosis in animals and humans. Microbiol Rev 1983;47:84-96.

4 Bennett M, Baxby D, Blundell N, Gaskell CJ, Hart CA Kelly DF. Cryptosporidiosis in the domestic cat. Vet Rec 1985;116:73-4.

5 Casemore DP, Jessop EG, Douce D, Jackson FB. Cryptosporidium plus campulobacter: an outbreak in a semirural population. J Hyg (Lond) 1986;96:95-105.

6 Freidank H, Kist M. Cryptosporidia in immunocompetent patients with gastroenteritis. Eur J Clin Microbiol 1986; patients

7 Baxby D, Hart CA, Taylor C. Human cryptosporidiosis: a possible case of human cross-infection. Br Med J 1983, 287:1760-1.

8 Wiedermann BL, Kaplan SL, Marino B. Prevalence and significance of cryptosporidiosis in children. Pediatr Infect Dis J 1985;4:292-3.

9 D'Antonio RG, Winn RE, Taylor JP, et al. A waterborne outbreak of cryptosporidiosis in normal hosts. Ann Intern Med 1985;103:886-8.

10 Isaac-Renton JL, Fogel D, Stibbs HH, Ongerth JE. Giardia and Cryptosporidium in drinking water. Lancet 1987; 973-4.

11 Rush BA, Chapman PA, Ineson RW. A probable waterborne outbreak of cryptosporidiosis in the Sheffield area. $J$ Med Microbiol 1990;32:239-42.

12 Joce R, Bruce J, Kiely D, et al. An outbreak of cryptosporidiosis associated with a swimming pool. Epidemio Infect 1991;107:497-508.

13 Anonymous. Swimming-associated cryptosporidiosis-Los Angeles County. Morbidity Mortality Weekly Repor 1990;39:343-5

14 Chapman PA, Rush BA, McLauchlin J. An enzyme immunoassay for detecting Cryptosporidium in faecal and environmental samples. J Med Microbiol 1990.32.233-7.

15 Ungar BLP. Enzyme-linked immunoassay for detection of Cryptosporidium antigens in fecal specimens. $J$ Clin Cryptosporidium antigen
Microbiol 1990;28:2491-5.

16 Chapman PA, Rush BA. Efficiency of sand filtration for removing cryptosporidium oocysts from water. $J$ Med
Microbiol 1990;32:243-5.

17 Nichols G, Thom BT. Screening for Cryptosporidium in stools. Lancet 1984;i:735.

18 Casemore DP, Armstrong M, Sands RL. Laboratory diagnosis of cryptosporidiosis. J Clin Pathol 1985;38:1337-41.

9 Healy GR. Laboratory diagnosis of amcebiasis. Bull $N Y$ Acad Med 1971;47:478-93.

20 Krogstad DJ, Spencer HC, Healy GR, Gleason NN, Sexton DJ, Herron CA. Amoebiasis: epidemiologic studies in the United States, 1971-1974. Ann Intern Med 1978;88: 89-97.

21 Garza D, Hopfer RL, Eisenbach S, Fainstein V. Fecal staining methods for screening Cryptosporidium oocysts. J Med Technol 1984;i:560-3.

22 Ma P, Soave R. Three-step stool examination for cryptosporidiosis in 10 homosexual men with protracted watery diarrhea. J Infect Dis 1983;147:824-8.

23 Logsdon GS. Cryptosporidium. J Am Water Workers Assoc 1988;80:14-27.

24 Ongerth JE, Stibbs HH. Identification of Cryptosporidium occysts in river water. Appl Environ Microbiol 1987;53: $672-6$

25 Musial CE, Arrowood MJ, Sterling CR, Gerba CP. Detection of Cryptosporidium in water using polypropylene cartridge filters. Appl Environ Microbiol 1987;53:687-92.

26 Rose JB, Cifrino A, Madore MS, Gerba CP, Sterling CR, Arrowood MJ. Detection of Cryptosporidium from waste-water and fresh-water environments. Water $S_{c i}$ Technol 1986;18:233-9.

27 Rose JB. Occurrence and significance of Cryptosporidium in water. J Am Water Workers Assoc 1988;80:53-8.

28 Stibbs HH, Ongerth JE. Immunofluorescence detection of Cryptosporidium oocysts in fecal smears. J Clin Microbiol 1986;24:517-21.

29 McLauchlin J, Casemore DP, Harrison DP, Gerson PJ, Samuel D, Taylor AG. Identification of Cryptosporidium oocysts by monoclonal antibody. Lancet 1987;i:51.

30 Sterling CR, Arrowood MJ. Detection of Cryptosporidium sp. infections using a direct immunofluorescent assay. sp. infections using a direct imm
Pediatr Infect Dis 1986;5:s139-42. 